\author{
M. Ossowski ${ }^{1}$, T. Moskalewicz ${ }^{2}$, A. Czyrska-Filemonowicz ${ }^{2}$, T. Wierzchońn $^{1}$ \\ ${ }^{1}$ Faculty of Materials Science and Engineering. Warsaw University of Technology, \\ Warsaw 02-507, Wołoska 141, Poland \\ ${ }^{2}$ AGH University of Science and Technology, Cracow, Poland
}

\title{
MODIFICATION OF THE MICROSTRUCTURE AND PROPERTIES OF LAMINATE TITANIUM ALLOY - TiAI INTERMETALLIC PHASES COMPOSITES BY A DUPLEX SURFACE ENGINEERING TREATMENT
}

\begin{abstract}
Laminate $\mathrm{TiAl}_{3}$ - titanium alloy composites have unique mechanical properties which result from a combination of the properties of the Ti-Al type intermetallic phases, such as the high stiffness and low density, and the properties of the titanium alloy, primarily its high ductility. These composite materials have already been used in industry, but their application is limited by the low resistance to frictional wear and to oxidation at elevated temperatures. The process of diffusion bonding of titanium alloys with an aluminum foil, followed by magnetron sputtering combined with glow discharge-assisted oxidizing, yields a gradient-type material, i.e. a laminate composite built of the $\mathrm{TiAl}_{3}$-reinforced titanium alloy with a diffusion surface layer of the $\mathrm{Al}_{2} \mathrm{O}_{3}+\mathrm{Ti}-\mathrm{Al}$ intermetallic phase type.

The paper presents the results of examination of the structure (by optical, SEM and TEM microscopy), phase composition, chemical composition, frictional wear resistance of the $\mathrm{Al}_{2} \mathrm{O}_{3}+\mathrm{Ti}_{\mathrm{x}} \mathrm{Al}_{\mathrm{y}}$ intermetallic composite surface layers produced on the composites, described above, by a duplex method that combines magnetron sputtering and plasma oxidizing processes. The composite surface layers have a diffusion character, and their microstructure, thickness and phase composition can be modified by modifying the parameters of the hybrid process, in particular the parameters of the glow discharge oxidizing, since these decide about whether the structure of the layer is nano-crystalline or fine-grained and thereby about the properties of the laminate composite.
\end{abstract}

Key words: composites, trialuminides, tribological properties, coatings, wear-resistant applications

\section{INTRODUCTION}

Because of their advantageous properties, titanium alloys and intermetallic phases of the Ti-Al system are increasingly used in industry. By combining the properties of titanium alloys, such as the high corrosion resistance, plasticity, good mechanical properties (including the fatigue strength) with the high resistance to oxidation at elevated temperatures and the higher Young modulus (in the $\mathrm{TiAl}_{3}$ phase -almost doubled compared to that of titanium alloys) of the intermetallic phases we can obtain a constructional material with unique properties. This can be achieved by producing laminate composites of the titanium alloy- $\mathrm{TiAl}_{3}$ intermetallic phase type using diffusion bonding of the titanium alloy with aluminum. The laminate composites thus produced 
have good mechanical properties and high fracture toughness, whereas the $\mathrm{TiAl}_{3}$ phase (Young modulus-216GPa against about 120GPa of the Ti6Al2Cr2Mo titanium alloy) constitutes the reinforcing phase of the composite. Other characteristic features of the composites are the high magnitude of compressive stresses active in $\mathrm{TiAl}_{3}$ aluminide and the diffusive character of the transition zone formed at the interface between the titanium alloy and $\mathrm{TiAl}_{3}$ [1-5]. This is why these composites, known as the metallicintermetallic laminates (MIL), arouse increasing interest in industry. The only drawback which lies in that titanium and its alloys, which form the outer zones of the composite, show poor resistance to frictional wear, can be eliminated by subjecting the composite to various surface treatments such as glow discharge assisted nitriding or carbonitriding [6-8]. Moreover, binary titanium alloys, which are used in industry most often because of their high fatigue strength, have however a relatively low resistance to oxidation at temperatures above $550^{\circ} \mathrm{C}$ [9]. This is due to the fact that the scale which forms during the high-temperature oxidation is structurally defected and contains not only rutile $\left(\mathrm{TiO}_{2}\right)$ but also the $\mathrm{Al}_{2} \mathrm{O}_{3}$ oxide; these two oxides differ in their thermal expansion coefficients which results in the scale being liable to spalling and further oxidation. A significantly better resistance to high-temperature oxidation is shown by intermetalic phases of the Ti-Al system, in particular titanium aluminides with an increased aluminum content, since the increased amount of aluminum oxides in the scale constitutes an effective barrier to diffusing oxygen. Therefore, the performance properties of the titanium alloys and laminate titanium alloy/ Ti-Al intermetallic phase

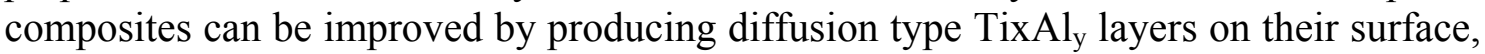
which will guarantee their good adherence to the substrate [10-13].

\section{EXAMINATION METHODS}

Laminate composite of the titanium alloy/ Ti-Al intermetallics / titanium alloy type (or multiple of this arrangement) were produced by diffusion bonding of a Ti6Al2Cr2Mo titanium alloy sheet $1 \mathrm{~mm}$ thick with an aluminium foil of the thickness of $0,3 \mathrm{~mm}$. The diffusion bonding process parameters were: temperature $\mathrm{T}=530^{\circ} \mathrm{C}$, load $\mathrm{P}=4 \mathrm{MPa}$, and process duration $\mathrm{t}=2 \mathrm{~h}$. The composite was then subjected to a hybrid process which consisted of producing an aluminium coating about $5 \mu \mathrm{m}$ thick by magnetron sputtering and then subjected it to glow discharge oxidizing carried out in $\mathrm{N}_{2}+$ air (4\%) atmosphere at the temperatures $\mathrm{T}=580^{\circ} \mathrm{C}(2 \mathrm{~h})$ and $630^{\circ} \mathrm{C}(1 \mathrm{~h})$ under the pressure in the reaction chamber $\mathrm{p}=4 \mathrm{hPa}$ (Fig.1.) 


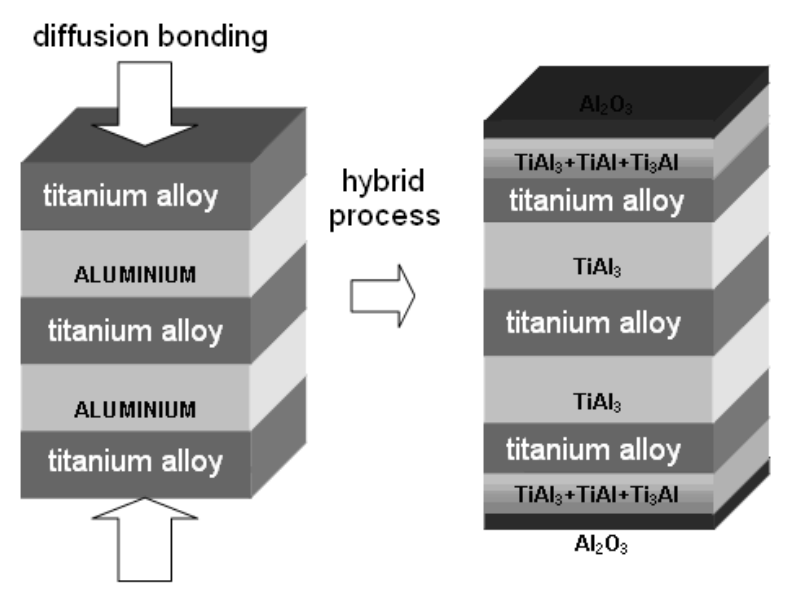

Fig. 1. Schematic representation of fabrication of the laminate titanium alloy- $\mathrm{TiAl}_{3}$ composite with surface $\mathrm{Al}_{2} \mathrm{O}_{3}+\mathrm{Ti}-\mathrm{Al}$ intermetalics type composite layers

The microstructure and phase composition of laminate composite thus obtained were examined in a scanning electron microscope (Hitachi S-3500N) equipped with an EDS detector, a transmission electron microscope (Jeol JEM 2010ARP), and an X-ray diffractometer (Brucker D-8 Advance) with $\mathrm{CoK} \alpha$ radiation. The shear tests were conducted in an Instron 1115 device (Fig.2), three test samples were cylindrical in shape with a diameter of $25 \mathrm{~mm}$, the load during the test was changed from 0 to $50 \mathrm{kN}$, speed of cross-bar displacement was $2 \mathrm{~mm} / \mathrm{min}$.

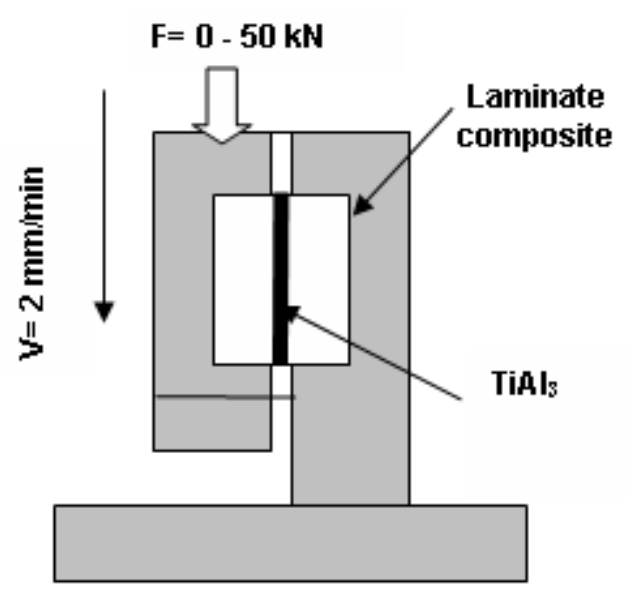

Fig. 2. Schematic diagram of the shear test holder

The frictional wear resistance was measured by the "three rollers + tapper" method (modified four ball method) under a unit load of 400MPa [14]. In this test, friction is applied between three cylindrical specimens (rollers) with surface layers formed of them and a rotating conical counter specimen (taper) at a velocity of 576 revolutions per minute. The counter specimens were made of AISI 1045 steel (30HRC) or HSS steel (64HRC). The test duration is 100 minutes, after each 10 minute cycle the measurement of wear depth are taken and new value of counter specimen load is apply to keep constant- unit load of 400MPa. 


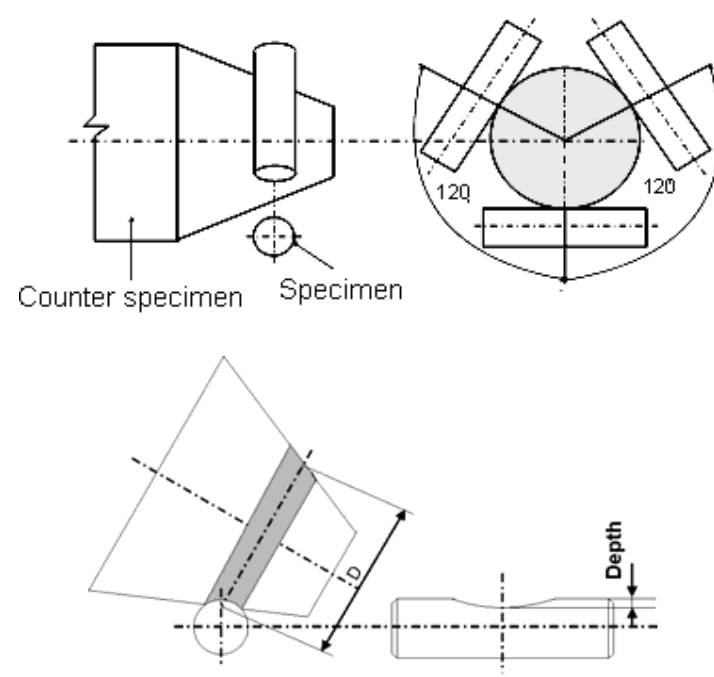

Fig. 3. Schematic diagram of the "three rollers + tapper" method

\section{RESULTS}

Figures 4 show the structure of the laminate titanium alloy/Ti-Al intermetallic phases composite produced by diffusion bonding, and the microstructure of the $\mathrm{TiAl}_{3}$, and the transition zone formed between the reinforcing phase ( $\mathrm{TiAl}_{3}$ aluminide) and the Ti6Al2CrMo titanium alloy, respectively.

a)

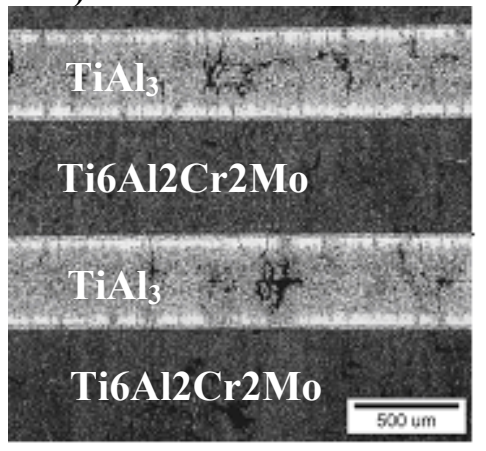

b)

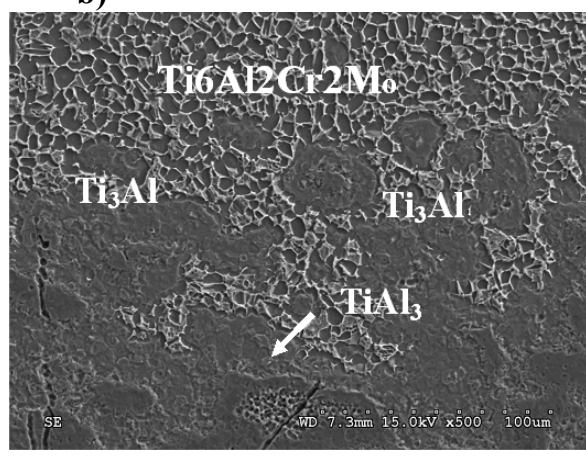

c)

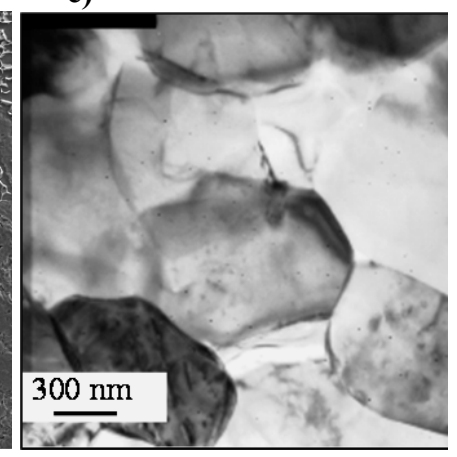

Fig. 4. Microstructure of the laminate $\mathrm{Ti} 6 \mathrm{Al} 2 \mathrm{Cr} 2 \mathrm{Mo} / \mathrm{TiAl}_{3}$ intermetallic phase composite (a), the transition zone between the $\mathrm{TiAl}_{3}$ reinforcing phase and the titanium alloy (b), and TEM microstructure of the $\mathrm{TiAl}_{3}$ phase (c)

The thickness of the reinforcing phase was about $300 \mu \mathrm{m}$ and its chemical composition was homogeneous within the entire volume. The content of titanium was about 27 at. $\%$ and that of $\mathrm{Al}$ was $73 \mathrm{at} \%$. Examinations of the chemical composition and phase composition of the transition regions show that those formed between the $\mathrm{TiAl}_{3}$ phase and the titanium alloys are composed of Ti-Al intermetallic phases $\left(\mathrm{TiAl}_{2}, \mathrm{TiAl}_{1}, \mathrm{Ti}_{3} \mathrm{Al}\right)$ arranged so that their aluminum content decreases as we pass nearer to the titanium alloy, whereas the $\mathrm{TiAl}_{3}$ aluminide has a fine-grained structure (grain size $\leq 1 \mu \mathrm{m}$ ) (Fig.4c). The shear strength of the composite was of the order of $92 \mathrm{MPa}$. 


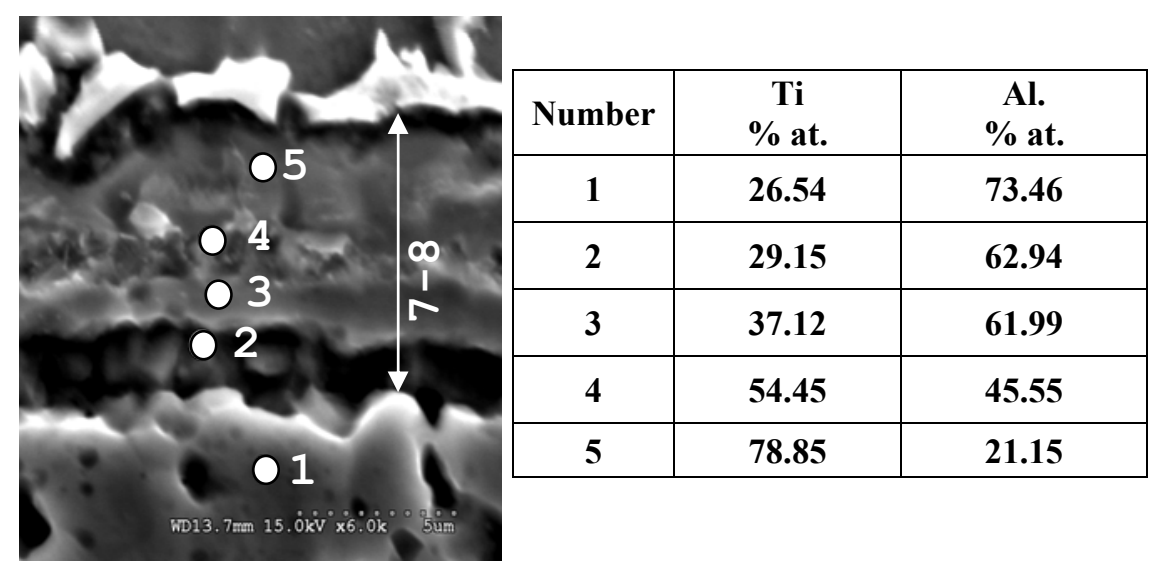

Fig. 5. Chemical composition of the transition zone $\mathrm{TiAl}_{3}$ reinforcing phase/Ti6Al2Cr2Mo alloy

The laminate composite thus produced was then subjected to the hybrid surface treatment which yielded a surface layer of the $\mathrm{Al}_{2} \mathrm{O}_{3}+\mathrm{TiAl}_{3}+\mathrm{TiAl}+\mathrm{Ti}_{3} \mathrm{Al}$ type (Fig.6).

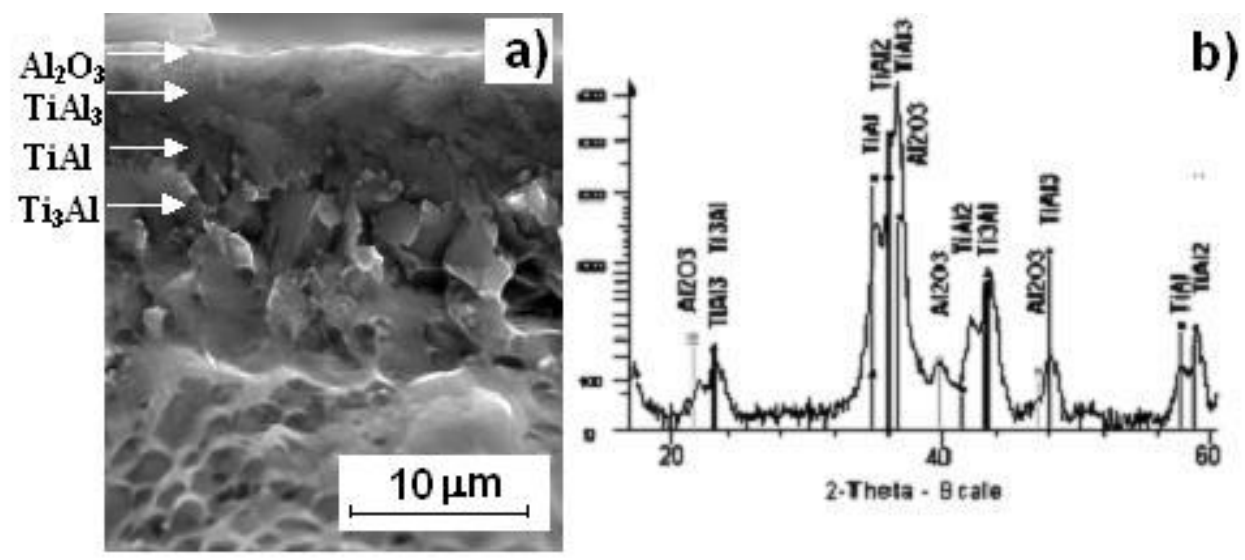

Fig. 6. Fracture (a) and diffractogram (b) of the $\mathrm{Al}_{2} \mathrm{O}_{3}+\mathrm{TiAl}_{3}+\mathrm{TiAl}+\mathrm{Ti}_{3} \mathrm{Al}$ composite layer on laminate composite

The phase composition of the surface layers formed due to the mutual diffusion of aluminum and titanium that proceeds during the hybrid process depends on the parameters of the glow discharge oxidizing and on the thickness and microstructure of the aluminium coating. It should be noted that the intermetallic phases formed during the hybrid process have nanocrystalline or fine-grained structures, and such has the $\alpha$ $\mathrm{Al}_{2} \mathrm{O}_{3}$ alumina formed in the outer zone of the composite layer as the result of the oxidizing process (Figs.7 and 8). 

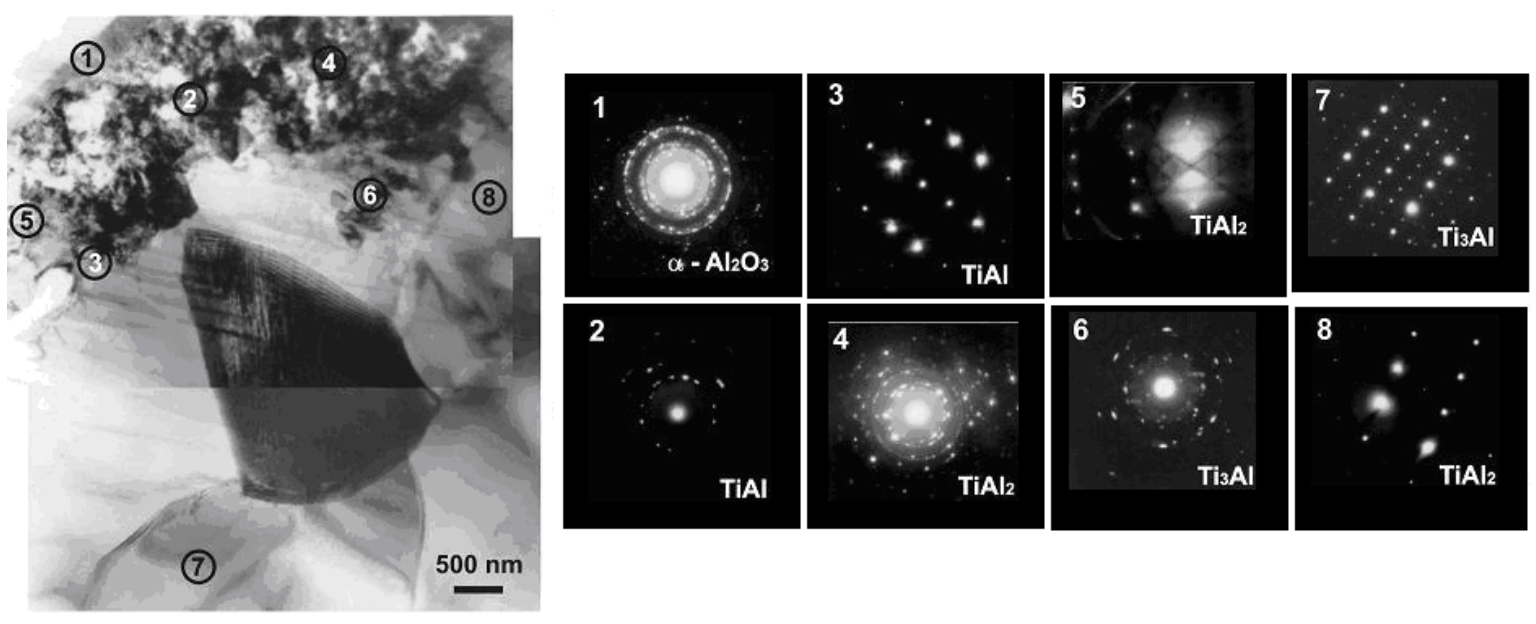

Fig. 7. TEM microstructure of a composite layer produced on the Ti6Al2Cr2Mo titanium alloy at a temperature of $630^{\circ} \mathrm{C}$

a)

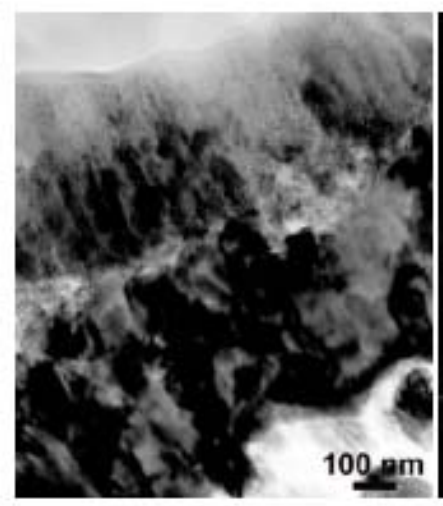

b)

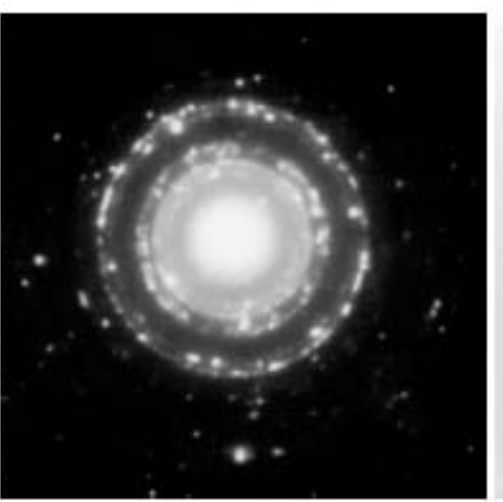

c)

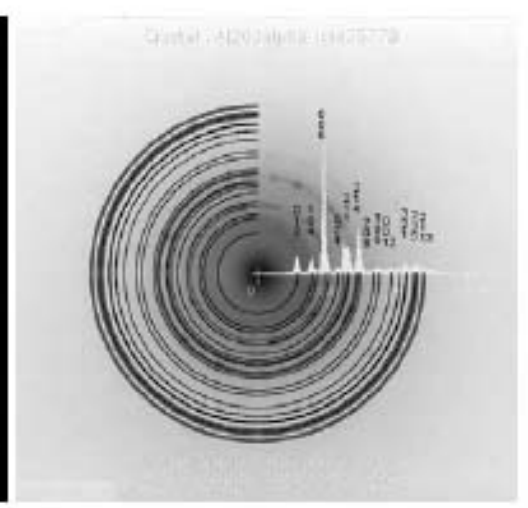

Fig. 8. Exemplary TEM microstructure (a) and electron-diffractogram (b) of $\alpha-\mathrm{Al}_{2} \mathrm{O}_{3}$ aluminum oxides

The possibility of producing fine-grained or nano-crystalline structures of the intermetallic phases and also of the aluminum oxide that build the composite layer guarantees an improvement of the performance properties of the laminate composite, in particular the increase of its hardness from about 480 to $1200 \mathrm{HV} 0.05$ and a considerable increase of its frictional wear resistance.

During the 100 minutes of friction test the composite material with $\mathrm{Al}_{2} \mathrm{O}_{3}+$ intermetallic phases type surface layer show significantly better wear resistant then Ti6Al2Cr2Mo titanium alloy after only 20 minutest of friction time. Further investigations with counter specimen made of high speed steel which harness was 60 HRC show still very good behavior of produced layers. 


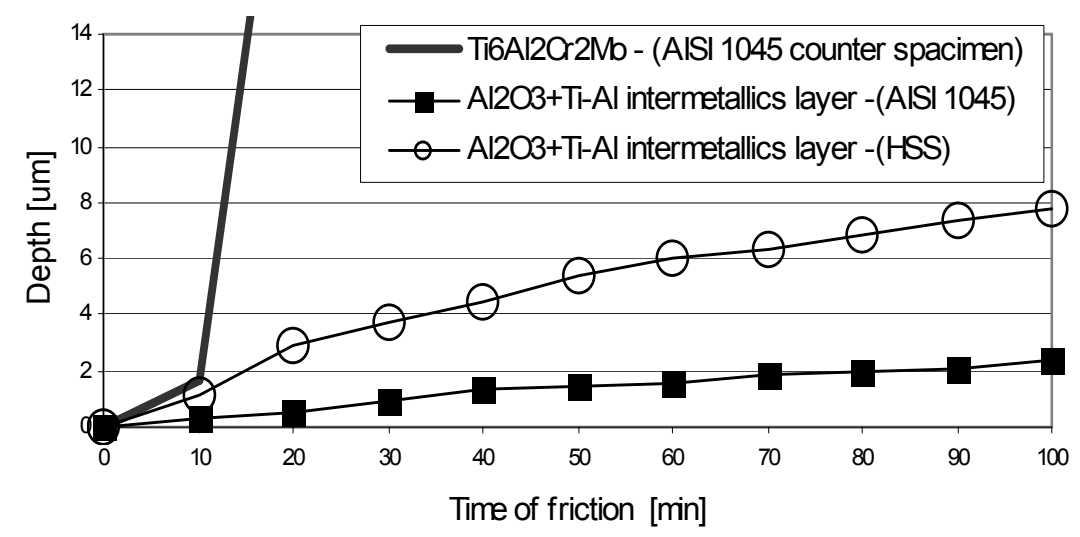

Fig. 9. Linear wear of the $\mathrm{Al}_{2} \mathrm{O}_{3}$ +intermetallic phases formed on the laminate composite as a function of the friction time ( HSS-64HRC and AISI 1045-30HRC counter specimen) compared with the wear behavior of the Ti6Al2Cr2Mo alloy (unit load 400MPa)

a)

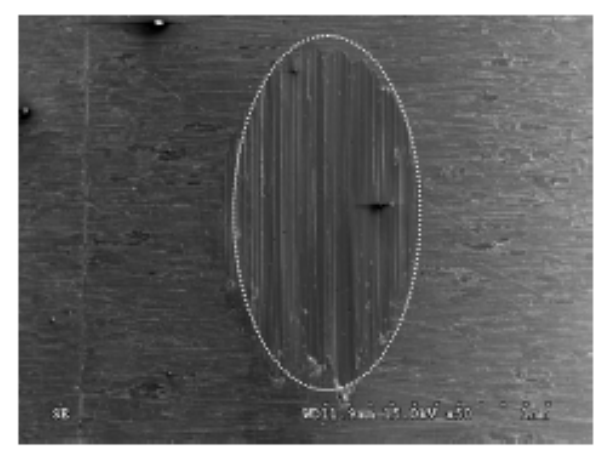

b)

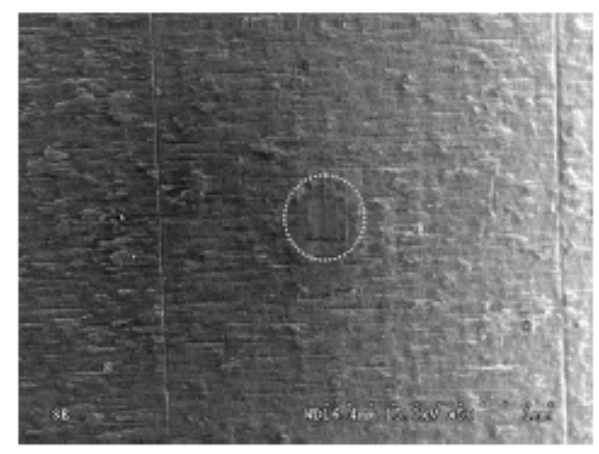

c)

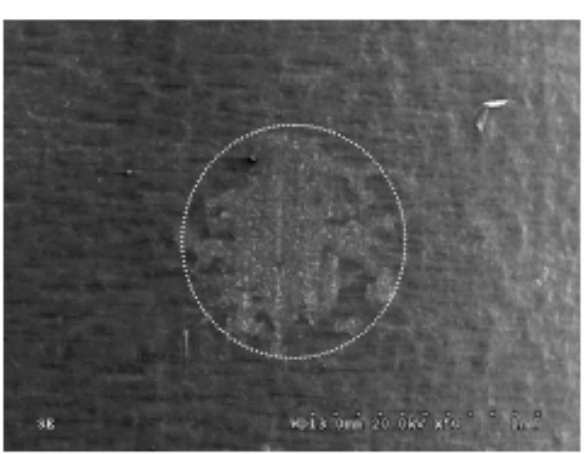

Fig. 10. SEM microphotographs of wear observed on Ti6Al2Cr2Mo titanium alloy (after 20min of friction) (a) and $\mathrm{Al}_{2} \mathrm{O}_{3}+$ intermetallic phases type layers with AISI 1045 (b) and HSS (c) counter specimen 


\section{CONCLUSIONS}

The laminate titanium alloy - $\mathrm{TiAl}_{3}$ aluminide composites with the surface layers built of the $\mathrm{Al}_{2} \mathrm{O}_{3}+\mathrm{Ti}-\mathrm{Al}$ intermetallic phases have a lower density and a higher frictional wear resistance than the titanium alloy. The $\mathrm{TiAl}_{3}$ reinforcing phase is bonded with the titanium alloy via diffusion. The transition zone contains the TiAl and $\mathrm{Ti}_{3} \mathrm{Al}$ phases which are more plastic and ensure good adhesion of the $\mathrm{TiAl}_{3}$ phase to the titanium alloy. The laminate titanium alloy $/ \mathrm{Ti}_{3} \mathrm{Al}$ composite with the intermetallic surface layer is characterized by a unique combination of the advantageous properties of binary titanium alloys (good mechanical properties, plasticity), intermetallic phases (high resistance to oxidation at elevated temperatures), and the $\mathrm{Al}_{2} \mathrm{O}_{3}$ aluminum oxide (high resistance to corrosion, heat-corrosion and wear). In view of these unique properties, the laminate composites can be considered to be new attractive constructional materials suitable for a wide variety of industrial applications.

\section{REFERENCES}

1. Rohatgi, D.J.Harach, K.S. Vecchio, K.P. Harvey, Resistance-curve and fracture behavior of $\mathrm{Ti}-\mathrm{Al}_{3} \mathrm{Ti}$ metallic-intermetallic laminate (MIL) composites, Acta Materialia, 51 (2003), pp.2933-2957.

2. Vecchio K.S., Synthetic Multifunctional Metallic-Intermetallic Laminate Composites, JOM, 3 (2005), pp.25-29.

3. Wierzchoń T., Ossowski M., Advances in Science and Technology, Structure and Properties of $\alpha \beta$ Titanium Alloy- TixAly Intermetallic Phases Laminate Composite 45 (2006), pp.1287-1292.

4. Peng L.M., Wang J.H., Li H., Zhao J.H., He L.H., Synthesis and microstructural characterization of $\mathrm{Ti}-\mathrm{Al}_{3} \mathrm{Ti}$ metal-intermetallic laminate (MIL) composites, Scripta Materialia, 52 (2005), pp.243-248.

5. Kainuma R., Sato J., Ohnuma I., Ishida K., Phase stability and interdiffusivity of the L10-based ordered phases in Al-rich portion of the Ti-Al binary system, Intermetallics 13 (2005), pp. 784-791.

6. Rolinski, G. Sharp, D.F. Cowgill, D.J. Peterman, Ion nitriding of titanium alpha plus beta alloy for fusion reactor applications, J. Nucl. Mater., 252 (1998), pp.200-208.

7. Czyrska-Filemonowicz A., Buffat P.A., Łucki M., Moskalewicz T., Rakowski W., Wierzchon T., Transmission electron microscopy and atomic force microscopy characterisation of titanium-base alloys nitrided under glow discharge, Acta Materialia 53, 16 (2005), pp. 4367-4377.

8. Sobiecki J.R., Wierzchoń T., Structure and properties of plasma carbonitrided Ti-6Al-2Cr-2Mo alloy, Surf. And Coat. Tech. 200(2006), pp. 4363-4367.

9. Lutering G., Williams J.G., Titanium, Springer-Verlag, Berlin, Heidelberg, 2003. 
10. Wierzchon T., Garbacz H., Ossowski M., Structure and properties of Ti-Al intermetallic layers produced on titanium alloys by duplex treatment, Mat. Sci. Forum., 475-479 (2005), pp. 3883-3886.

11. Deqing W., Ziyuan S., Yingli T., Microstructure and oxidation of hot-dip aluminized titanium at high temperature, Applied Surface Science 250 (2005), pp. 238-246.

12. Liu Z. , Wang G., Improvement of oxidation resistance of $\gamma$-TiAl At 800 and $900^{\circ} \mathrm{C}$ in air by TiAl2 coatings, Materials Science and Engineering A 397 (2005), pp. 50-57. 